\title{
The Impact of Human Resource Management Practices of Sharing Workers on Service Performance
}

\author{
Liping Liao' Yinhua Gu * and Jing Wang \\ School of Management Science, Chengdu University of Technology, Chengdu, China \\ * Correspondence: Yinhua Gu,guyh@,cdut.edu.cn
}

Keywords: sharing economy, sharing workers, human resource management practices, service performance, work engagement.

\begin{abstract}
Based on the Organizational Support Theory, this study examines the relationship between human resource management practices and service performance of sharing workers by demonstrating the mediation role of work engagement. We tested this theoretical model using an in-person interview questionnaire survey of 318 downwind drivers. Results showed that: (1) the main effect of human resource management practices of sharing workers on service performance was significant; (2) work engagement played a prominent mediation role between human resource management practices and service performance of sharing workers; (3) the mediation role of employee vigor between the platform incentives and the performance of employee services was significant; (4) employee dedication had an obvious and indirectly positive mediating effect between sharing workers' dimensions of human resource management practice and their service performance; (5) employee absorption on the mediation role between the various dimensions of the sharing human resources management practices (platform support, platform incentives and platform constraints) and employee service performance was significant. This study has important value for the study on human resource management practices in the context of sharing economy, and provides practical enlightenment for employee management of the sharing economy platform.
\end{abstract}

\section{Introduction}

Nowadays, the economic strength in China continues to increase, giving birth to emerging economic models and business forms. Based on the Internet economic background, the sharing economy has come into being, and the sharing platform has brought a tremendous impact on people's lives ${ }^{[1]}$. In the US Time Magazine (2011), it is called as one of the ten creative ideas that can change the world (Chase,2015) ${ }^{[2]}$. Although many questions about the sharing economy have not yet been answered, the development of the sharing economy is a general trend and has been met with scholars' acquiescence ${ }^{[3][4][5][6][7]}$. In the related fields of management, the involved 
researches mainly include business management ${ }^{[8][9]}$, hotel management ${ }^{[10][11][12]}$, information management ${ }^{[13]}$ and so on. In terms of organizational management, the sharing economy has not only brought about changes in the external environment to human resource management, but also affects its internal structure.

As an emerging model relying on the Internet platform, the sharing economy has spawned new human resource management. Taking the sharing platform of the research object in this study as an example, the current internal human resources of the "special car" platform are mainly divided into two parts: one is a core functional team which is similar to the traditional organization; the other is the suppliers of unique idle resources within the shared platform organization. The emergence of this type of special human resources has caused scholars to scramble for discussion, and they have a delicate relationship with their sharing platform: they are both "employees" and "customers". However, this study believes that such special human resources are not only suppliers of sharing resources, but also demanders of resources from a certain perspective, because they have three distinct "sharing": "background sharing", "capital sharing" and "work platform sharing". Therefore, this study follows the concept of Sharing Workers, and calls the management and service of sharing workers by sharing platform enterprises as Sharing Human Resource Management ${ }^{[14]}$. The sharing human resource management practice was proposed in 2017. Based on the research of enterprises and employees in sharing platforms, scholars introduced the concept of sharing human resource management practice into the human resource management of sharing workers for the first time in their report ${ }^{[15]}$. The sharing human resource management practice refers to a series of human resource policies and corresponding management activities of sharing platform enterprises.

There are relatively few empirical researches on the network ride-hailing driver from the perspective of human resource management. The main viewpoints are focused on the theoretical research of human resource management models, labor relationship management and so on. Some scholar suggests that the sharing economy obscured the three characteristics of the difference between producers and consumers, the relationship between employment and being employed, and freelance cooperative relations ${ }^{[16]}$. When studying the field of "sharing travel", Hartl et al. (2015) think that it is necessary to build the "semi-attached" production relationship with enterprises through a "tripartite agreement" or a "quartet agreement"[17], and Cramer and Krueger (2016) believe that Uber drivers and passengers who use ride-hailing technology can match more efficiently ${ }^{[18]}$. The relationship between employees and organizations within a sharing platform enterprise has changed. Only by finding a human resources management practice that differs from the traditional one can we better manage such emerging talents. Compared with traditional formal employees, this type of employee's special dual identity makes management more challenging and exploratory. First, the human resources mobility within the sharing platform is very high, sharing workers downplay post differences and post specifications, and traditional human resource planning no longer makes sense. Secondly, the threshold of sharing platforms is very low and the traditional recruitment mechanisms cannot be applied any more. At the same time, the training of sharing workers is also different 
from traditional human resource management and they mainly adopt non-mandatory online school training. Finally, the salary management based on one of the six functional sectors of traditional human resource management cannot be implemented, the base salary of sharing workers is zero, and the direct influence of salary is the time of work and the quality of services. The major functional sectors of traditional human resource management are no longer applicable in the management of sharing human resources. Therefore, scholars have explored the management practice applicable to this kind of special human resources based on sharing human resources. And the management models and management practices based on traditional human resources are no longer applicable to human resources management within the sharing economy platforms. Meanwhile, the connotations and dimensions and other related content of sharing human resource management are also lacking. The concept of "sharing workers' human resource management practice" provides a new perspective for research on sharing workers.

As an internal employee of a service industry, there are many factors that affect employee service performance, most of which are based on the psychological mechanism. Employee service performance usually refers to the employees' achievement of relevant organizational goals in controlling self-behavior. For service platforms, a high level of service quality is the basis for high customer loyalty and high satisfaction. As a conveyor belt between platforms and customers, the service quality of employees determines customer satisfaction, while employee behavior is the external carrier of service quality. Therefore, employee service performance can be defined as the behavior of employee to serve and help customers. Service behaviors within the control of employees will bring high quality of service, but there are still uncontrollable behaviors of employees, such as the impact of organizations on employees. Hence, measuring service performance of employees by behavior is less. In summary, this study defines employee service performance as the behavior of employees serving and helping clients at work ${ }^{[19]}$. From the perspective of organizational support theory, the more engagement in work the employees show, the higher work performance will be achieved in general. Thus, the work engagement can greatly affect the improvement of work performance, and the relationship between the two is very close ${ }^{[20]}$. At present, there are too few studies of human resource management practices in sharing platform enterprises on employee service performance, and there is less research on what conduction mechanisms the human resources management practices of sharing employees can use to influence the service performance of sharing employees. For sharing platform companies, whether human resources management practices of sharing workers can affect the service performance of sharing workers through work engagement has not been verified.

Based on the above issues, this study conducts empirical research with 318 downwind drivers as the survey object on the basis of the pre-theoretical research, and builds a theoretical model to explore the relationship among sharing human resource management practices, work engagement and employee service performance, so as to enrich related theoretical research and provide references and suggestions for the internal human resource management practices of sharing platform enterprises. 


\section{Materials and Methods}

\subsection{Theoretical Background and Hypothesis}

\subsubsection{Human resource management practice and service performance of sharing workers}

Human resource management practice is an important human resource management activity of the company, which affects the company's final performance. It refers to the general term for various systems, methods, and policies that affect employees' attitudes and behaviors and then employee performance. Modern enterprises try to influence employee service performance by continuously optimizing human resource management practices. At present, the research on the relationship between the two in the academic world is mainly from two perspectives, one is the research model and the other is the mechanism of action. Based on the organizational support theory, when an organization adopts a series of management practice activities including platform support, platform incentives and platform constraints, employees will generate good service performance.

First, support from the organizational level can meet the needs of employee belonging, self-esteem, and recognition, so employees are well motivated to make a positive contribution to the organization voluntarily, and their better work performance may be inspired. Employees are willing to stay in the organization and contribute to it because the organization cares and values its employees who act based on reciprocity and return to the organization through continuous actions ${ }^{[21][22]}$. Human resource management practices are an important source of organizational support ${ }^{[23]}$. The sharing platform supports employees based on their needs, helping them comb their confidence, appeals, and resolve issues. It has a positive psychological impact on employees to a large extent and employees feel in the support of the organization, thereby bringing good service performance. Previous researches have shown that organizational support has a significant positive impact on employees' organizational commitments $^{[24]}$ and service performance ${ }^{[25]}$.

H1a: Platform support of sharing human resource management practices has a significant positive impact on employee service performance

Then, organizational motivation, to motivate employees, can make employees in the organization motivate, proactive and creative ${ }^{[26][27]}$, and promote their hard work behaviors $^{[28][29]}$. Effective motivation will ignite the passion of employees, make them more motivated to work, allow them to generate desires that transcend themselves and others, and unleash the potential huge internal driving force to contribute their enthusiasm for the company's vision. Scholars have found that effective incentive mechanisms can not only improve employee autonomy, but also increase their organizational commitment ${ }^{[30]}$.

H1b: Platform incentives of sharing human resource management practices have a significant positive impact on employee service performance

Finally, when there is a clear constraint on the behavior of employees in the organization, based on personal challenges, employees will face their work with a positive attitude ${ }^{[31][32]}$. Sharing platforms also have certain systems and guidelines to 
regulate employees' behaviors and restrict their performance within behavioral roles. As sharing workers, if they do not comply with the platform organization's system specifications, they will be sealed. Only within the constraints of the system can there be more job opportunities and better work performance.

H1c: Platform constraints of sharing human resource management practices have a significant positive impact on employee service performance

\subsubsection{Mediation of employee vigor}

Employee vigor refers to the tenacious perseverance and infinite enthusiasm that individuals have when working, and can maintain a good communicative relationship with them when not working. It is a positive emotional response in work engagement ${ }^{[33]}$. Kahn (1990) is the first scholar to put forward the concept of work engagement. And then scholars study it from different perspectives, for example, in empirical research based on family and work engagement, scholars have found that work engagement is not a simple single-dimensional variable(Rothbard, 2001 ${ }^{\text {[34] }}$; May, Gilson \& Harter, 2004 ${ }^{[35]}$; Rich, LePine, \& Crawford 2010 ${ }^{[36]}$.etc.). The relationship between sharing human resource management practices and employee service performance shouldn't be directly linked, but a more complex functioning process. According to previous literatures, human resource management practices exert an effect on employee service performance levels by influencing individual behaviors.

First, sharing human resource management practices affect employee vigor. The organization's human resources management practice activities are organized around employees, and everything in the organization, including supportive, restrictive, and motivational management methods, is designed to influence employees' psychology and behaviors. Based on organizational support theory, sharing human resource management practices provide employees with organizational resources through supporting practical activities such as caring for employees' feedback and helping employees solve problems to achieve goals; motivational practical activities will inject new motivation for employees; restrictive practice management can standardize employees' work behaviors and create a fair atmosphere for employees. Thus, in return, employees will work with a more positive attitude, which reflects a high level of vigor. What's more, researches on human resource management practices and employee attitudes also shows that human resource management practices are more front-end influence factors to the psychological states such as work satisfaction, organizational commitment, and work engagement ${ }^{[37][38][39]}$. Saks (2006) targeted individual Canadian young employees and found that the sense of organizational support and the characteristics of job itself have a positive impact on work engagement ${ }^{[40]}$. The importance of the organization perceived by the employees in the organization and the organization's sense of identity to the employees and other work-related organizational resources have a positive role in promoting the employee's vigor ${ }^{[41]}$.

Next, employee vigor will affect employee service performance. As a positive working psychological state, employee vigor can influence individual behaviors. Employees with a high level of vigor will have a sense of belonging and identification with the organization, which can increase the involvement of employees in 
organizational activities and can make them willing to pursue organizational goals and eager to stay in the organization. Therefore, it's a mechanism to drive employees' positive organizational behaviors, which can foster the improvement of employee service performance levels. The study found that high-vigor employees tend to produce more organizational citizenship behaviors ${ }^{[22][43]}$, and service performance is exactly the embodiment of organizational citizenship behaviors. Based on it, the following assumptions are proposed:

H2a: Employee vigor mediates the relationship between platform support and service performance

$\mathrm{H} 2 \mathrm{~b}$ : Employee vigor mediates the relationship between platform incentives and service performance

$\mathrm{H} 2 \mathrm{c}$ : Employee vigor mediates the relationship between platform constraints and service performance

\subsubsection{Mediation of employee dedication}

Employee dedication means that individuals strongly agree with their work and take pride in it, and they will devote themselves to their work with full enthusiasm and actively face any difficulties and challenges when working ${ }^{[44]}$.

First, sharing human resource management practices positively affect employee dedication. Based on the organizational support theory, the organization will actively help employees solve problems in order to provide employees with corresponding organizational support. When their needs of organizational resources are met, employees will be highly engaged; when motivational measures are implemented in the organization, the employee's inner desire for the realization of self-worth is ignited, and they desire for organizational recognition and work with full enthusiasm; when the restrictive measures in the organization are implemented, employees gain fairly treatment form the organization and their jobs are highly recognized; when individuals within an organization realize that their work cannot meet their needs, they will be highly engaged. Belgian scholars (Bledow et al., 2011) found that the organization's overtime arrangements can affect the morning status of individuals in the company, and then affect the dedication level of IT employees ${ }^{[45]}$.

And next, employee dedication positively impacts service performance. When the employees' dedication level is higher, the individuals will more psychologically agree with the job and their behavior performance will be more ideal. While completing the tasks, they'll think about how to better offer some potential services to customers, so employee dedication has a positive impact on service performance. Based on it, the following assumptions are put forward:

H3a: Employee dedication mediates between platform support and service performance

H3b: Employee dedication mediates between platform incentives and service performance

H3c: Employee dedication mediates between platform constraints and service performance 


\subsubsection{Mediation of employee absorption}

Employee absorption means that individuals are immersed in happy work and always focus too much on their work to ignore time, which is a positive mental state $^{[46]}$.

First, sharing human resource management practices positively affect employee absorption. According to organizational support theory, the autonomy of work tasks and the way to assess the quality of work through customer satisfaction provide employees with platform resources. Employees don't have to worry about not being able to complete their work for the reason of not obtaining organizational resources; on the contrary, employees can pay attention to their own work and reduce their pressure because they have the organization support. Through a series of incentive mechanisms, employees are immersed in happy work because they are eager to get the organization's resources for the work; a series of restraint mechanisms, including fake penalties and even fake seals of the practice management, provide employees with a fair and harmonious organizational atmosphere. For employees, Rich et al. (2010) found that organizational support can significantly affect employee absorption in their research ${ }^{[47]}$. Kataria, Garg, and Rastogi (2013) found that employee absorption has a positive impact on the organizational performance and can predict it ${ }^{[48]}$.

Then, employee absorption positively affects service performance. When employees pay attention to work, they will generate happy positive emotions which can promote the performance of employee role behaviors. Rich (2010) found that employees' high levels of concentration can establish and strengthen the emotional connections with work, thereby enabling employees to show more in-role behaviors $^{[49]}$.Therefore, this study makes assumptions:

H4a: Employees absorption mediates between platform support and service performance

H4b: Employees absorption mediates between platform incentives and service performance

H4c: Employees absorption mediates between platform constraints and service performance

To sum up, the theoretical model of this study is shown in Figure 1.

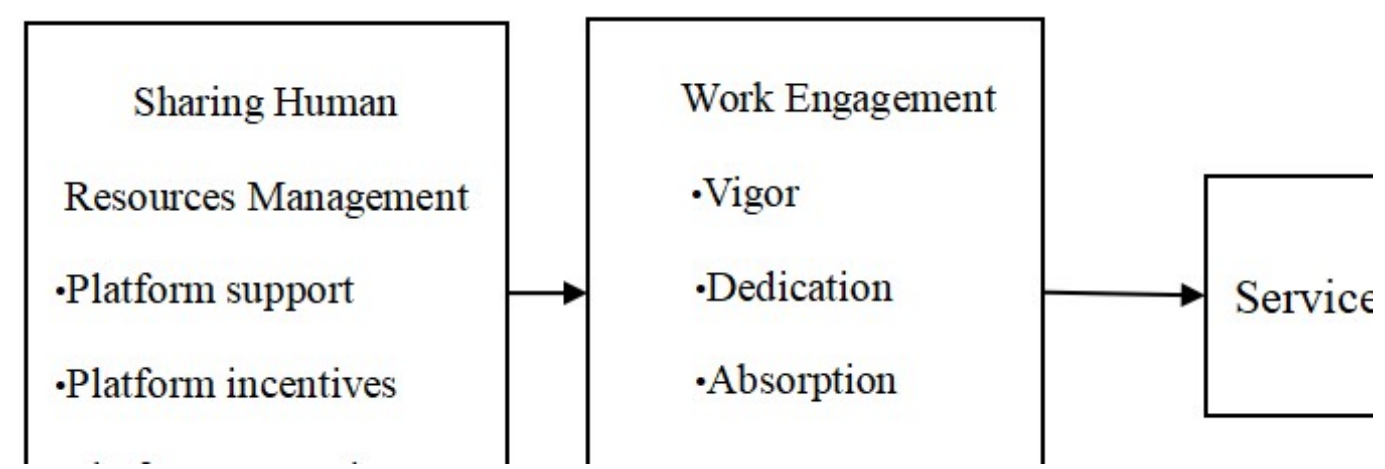

Figure 1. The Theoretical Model 


\subsection{Methods}

\subsubsection{Samples and Procedures}

In order to effectively ensure the quality of the data during the survey, the research used an in-person interview method to collect data. Using this method to collect data can avoid missing and wrong filling, and can also improve the effective recovery rate of the questionnaire and improve the data quality of the questionnaire. The research work of this study was conducted from February to April 2018 and the research targets include ride-hailing drivers in Chengdu, Suining, Mianyang and other places. Before the survey began, the researchers of the research group explained the purpose of the survey to the subjects, and carried out the survey after obtaining the consent of the subjects.

After the initial questionnaire was designed, the study was pre-tested prior to the formal survey in order to improve the reliability and validity of the measurement tool, and the pre-testing was performed and completed one week before the formal survey began. In the end, there are 118 valid questionnaires for small sample data collection and 318 valid questionnaires for large sample data collection, with an effective recovery rate of $94.08 \%$.

Among the effective samples recovered, in terms of the sex ratio, the vast majority were male, accounting for $93.6 \%$, showing that male workers made up the majority of the industry; judging from the length of their working hours on the online ride-hailing platform, the number of workers in about two years or so was $44.3 \%$, while among the remaining individuals, the proportion of persons who were less than 6 months was $8.8 \%$, the proportion of people in a year or so was $36.5 \%$, and the proportion of people in three years and more was $10.4 \%$; as to the age ratio, the three age groups(21-30, 31-40 and 41-50 years old) accounted for the majority of the proportion separately and reached $91.3 \%$ totally; in terms of education, the proportion of junior high schools and below was $33.6 \%$, the proportion of senior high school, middle school teachers and secondary schools was $25.5 \%$, and the proportion of tertiary education was $29.2 \%$.

\subsubsection{Measures}

All variables were assessed on the Likert five-point scale ranging from 1 (strongly disagree) to 5 (strongly agree). In order to ensure the consistency of the Chinese and English scales, a standard translation and back-translation procedure is employed for measurement tools of work engagement and service performance.

(1) Sharing Human Resource Management Practices. The scale used in the research developed by Gu Yinhua (2017) includes three dimensions including support, incentive, and constraint, with a total of 11 items. The survey object of this scale is the ride-hailing driver, which is consistent with the survey object of this paper. Among them, a representative sample item is "Didi Platform is good at helping you build confidence". Cronbach's $\alpha$ for this measure was 0.83 .

(2) Work engagement. Since this study was conducted in the context of Chinese culture, the work engagement scale mainly refers to the WES work engagement scale 
prepared by Schaufeli WB (2002) to measure the work engagement level of employees. A total of 17 items are formed and mainly divided into three dimensions: employee vigor, employee dedication, and employee absorption ${ }^{[50][51]}$. The Cronbach coefficients of the employee vigor scale, employee dedication scale, and employee absorption scale are $0.767,0.735$, and 0.753 , respectively. All three values are between 0.7 and 0.8 , so they have a considerable reliability; and the consistency coefficient of the total scale is about 0.9. The representative items are "I am happy to drive a downwind car when I wake up in the morning", "I feel energetic when driving a downwind car", "When I drive a downwind car, I have only this job full in my head". Cronbach's $\alpha$ for this measure was 0.90 .

(3) Service performance. Service performance refers to the behavior of employees in serving and helping customers during the work process, and it represents the effect of service to customers. In this study, we selected the employee service performance scale (from Borucki \& Burket ${ }^{[52]}$ and Liao \& Chuang ${ }^{[53]}$ ) of the relevant retail chain stores, with a total of 7 items. Among them, a representative item is "friendly to passengers and help them". The employee service performance evaluation in this study is a method by the subjects' self-assessment, allowing the subjects to evaluate their own service performance. Cronbach's $\alpha$ for this measure was 0.94 , which indicated the reliability of the scale was very good.

(4) Control variables. This study controls demographic variables that may affect the results, including gender, age, education, and length of time working on the ride-hailing platform.

\section{Results}

\subsection{Descriptive Statistics}

Table 1 presents the mean, standard deviations and correlation coefficient of each variable. From the correlation coefficient("r"), it can be seen that the platform support, platform incentive, platform constraint and service performance of the sharing human resource management practice are significantly related, and the correlation coefficients are $0.564,0.574$, and 0.582 , respectively; in the correlation analysis of work engagement and service performance, the correlation coefficients of employee vigor, employee dedication, employee absorption, and service performance were $0.573,0.647$, and 0.683 , respectively $(\alpha<0.01)$, which laid the foundation for the later test.

Table 1. Correlations, mean, standard deviations of all variables in the study $(\mathrm{N}=318)$

\begin{tabular}{llllllllllll}
\hline Variables & Mean & SD & 1 & 2 & 3 & 4 & 5 & 6 & 7 \\
\hline
\end{tabular}

1.Platform Support $\quad 3.5220 \quad 0.69125$

2.Platform Incentive $3.7028 \quad 0.720730 .593^{* *}$ 


\begin{tabular}{|c|c|c|c|c|c|}
\hline 3.Platform Constra & 3.6960 & 0.66496 & $0.501^{* *} 0.588^{* *}$ & & \\
\hline 4.Employee Vigor & 3.6394 & 0.67512 & $0.607^{* *} 0.596^{* *} 0.539^{* *}$ & & \\
\hline $\begin{array}{l}\text { 5.Employee } \\
\text { Dedication }\end{array}$ & 3.7075 & 0.68135 & $0.564^{* *} 0.496^{* *} 0.520^{* *}$ & $0.730^{* *}$ & \\
\hline $\begin{array}{l}\text { 6.Employee } \\
\text { Absorption }\end{array}$ & 3.6190 & 0.68705 & $0.601^{* *} 0.537^{* *} 0.512^{* *}$ & $0.743^{* *}$ & $0.684^{* *}$ \\
\hline $\begin{array}{l}\text { 7.Service } \\
\text { Performance }\end{array}$ & 3.7965 & 0.62747 & $0.564^{* *} 0.574^{* *} 0.582^{* *}$ & $0.573^{* *}$ & $0.647^{* *} \quad 0.683^{* *}$ \\
\hline
\end{tabular}

\subsection{Variable-Differentiated Validity Testing}

In this study, since the seven variables of platform support, platform incentives, platform constraints, employee vigor, employee dedication, employee absorption, and service performance were measured during the same survey period, a confirmatory factor will be applied to these seven variables Analysis to examine the validity of discriminating between variables (see Table 2). As can be seen from Table 2, the fit between model 4 and the hypothetical model in this study is the best ( $22 / \mathrm{df}=1.754$, $\mathrm{GFI}=0.959$, TLI $=0.949, \mathrm{CFI}=0.951, \mathrm{RMSEA}=0.054, \mathrm{NFI}=0.953)$. However, the fit indices of several other alternative models are significantly worse. It can be seen that there is a good discriminant validity between the 7 study variables.

Table 2. Comparative analysis of goodness of fit of the measurement model

\begin{tabular}{lccccccc}
\hline Model & Number of factors & x $2 / \mathrm{df}$ & GFI & TLI & CFI & RMSEA & NFI \\
\hline Model 1 & 1 & 6.658 & 0.925 & 0.939 & 0.911 & 0.134 & 0.932 \\
Model 2 & 2 & 5.263 & 0.949 & 0.933 & 0.931 & 0.116 & 0.950 \\
Model 3 & 3 & 3.595 & 0.950 & 0.931 & 0.944 & 0.087 & 0.951 \\
& & & & & & & \\
Model 4 & 7 & 1.754 & 0.959 & 0.949 & 0.951 & 0.054 & 0.953 \\
\hline
\end{tabular}

Note: N=318; Model1: SHRBP1+SHRBP2+SHRBP3+WE1+WE2+WE3+ESP; Model2:

SHRBP1+SHRBP2+SHRBP3, WE1+WE2+WE3+ESP; Model3: SHRBP1+SHRBP2+SHRBP3, WE1+WE2+WE3, ESP; Model4: SHRBP1, SHRBP2, SHRBP3, WE1, WE2, WE3, ESP.

SHRBP1: platform support; SHRBP2: platform incentives; SHRBP3: platform constraints; WE1: 
employee vigor; WE2: employee dedication; WE3: employee absorption; ESP: employee service performance.

\subsection{Hypothesis Testing}

\subsubsection{Direct effect testing}

SPSS version 23.0 was used to test the direct effects of the model. Table 3 shows the results of regression analysis of sharing human resource management practices on service performance.

Table 3. Results of regression analysis

\begin{tabular}{|c|c|c|c|c|c|c|}
\hline \multirow{2}{*}{ Variables } & & \multicolumn{5}{|c|}{ Service Performance } \\
\hline & & $\begin{array}{l}\text { Zero } \\
\text { model }\end{array}$ & Model 1 & Model 2 & $\begin{array}{l}\text { Model } \\
3\end{array}$ & Model 4 \\
\hline \multirow{4}{*}{$\begin{array}{l}\text { Control } \\
\text { variable }\end{array}$} & Gender & 0.005 & -0.076 & -0.047 & -0.038 & -0.069 \\
\hline & Age & 0.216 & 0.055 & 0.077 & 0.112 & 0.125 \\
\hline & Education & -0.037 & 0.008 & -0.027 & 0.001 & 0.010 \\
\hline & $\begin{array}{l}\text { Length of time working } \\
\text { on the ride-hailing } \\
\text { platform }\end{array}$ & 0.010 & 0.056 & 0.022 & 0.057 & 0.049 \\
\hline \multirow[t]{4}{*}{$\begin{array}{l}\text { Independent } \\
\text { variable }\end{array}$} & $\begin{array}{l}\text { Sharing Human Resource } \\
\text { Management Practices }\end{array}$ & & $0.379 * *$ & & & \\
\hline & Platform Support & & & $0.550 * *$ & & \\
\hline & Platform Incentive & & & & $0.561 * *$ & \\
\hline & Platform Constraint & & & & & $0.575 * *$ \\
\hline \multirow{4}{*}{$\begin{array}{l}\text { Summary of } \\
\text { regression } \\
\text { models }\end{array}$} & $\mathrm{R}^{2}$ & 0.046 & 0.477 & 0.327 & 0.348 & 0.363 \\
\hline & $\triangle \mathrm{R}^{2}$ & 0.046 & 0.432 & 0.316 & 0.338 & 0.353 \\
\hline & $\mathrm{F}^{2}$ & 6.108 & $10.229 * *$ & $18.789 * *$ & $4.346 * *$ & $10.946^{* *}$ \\
\hline & $\triangle \mathrm{F}^{2}$ & 6.108 & $28.984 * *$ & $88.223 * *$ & $7.298 * *$ & $33.021 * *$ \\
\hline
\end{tabular}

As can be seen from Table 3, the human resource management practice of sharing workers has a significant positive impact on service performance $\left(\triangle \mathrm{F}^{2}=\right.$ 
28.984, $\mathrm{p}<0.01$ ), which can prove that $\mathrm{H} 1$ is initially established. Platform support can significantly predict service performance $\left(\triangle F^{2}=88.223, p<0.01\right)$, assuming H1a is established; platform incentives have significant predictive effects on service performance $\left(\triangle \mathrm{F}^{2}=7.298, \mathrm{p}<0.01\right)$, assuming $\mathrm{H} 1 \mathrm{~b}$ is established; platform constraints can Significantly predict service performance of employees $\left(\triangle F^{2}=33.021, p<0.01\right)$, assuming H1c holds.

\subsubsection{Mediating effect testing}

In view of the shortcomings of the previous testing methods of mediation effects, we use the Bootstrap analysis proposed by Preacher \& Hayes (2004) to test the mediation effects ${ }^{[54]}$ and to perform the mediation variable test. The sample size is set to 5000 , the confidence interval is set to $95 \%$, and the sampling method is selected as the non-parametric percentile method of deviation correction. If the mediation test results show that the confidence interval of deviation correction doesn't contain 0 , the mediation effect is significant. In order to further analyze the mediation paths and the relationship of the paths between sharing human resource management practices and employee service performance and, we also conducted further path analysis:

Table 4. Mediation test results

\begin{tabular}{clccc}
\hline \multirow{2}{*}{ Mediation variable } & Independent variable & \multicolumn{2}{c}{ Confidence interval } & \\
\cline { 3 - 4 } & & \multicolumn{2}{c}{ Low value } & High \\
value & \\
\hline \multirow{2}{*}{ Employee Vigor } & Platform Support & -0.1123 & -0.0207 & -0.0433 \\
& Platform Incentive & -0.1633 & -0.0028 & -0.0766 \\
& Platform Constraint & -0.1046 & -0.0122 & -0.0443 \\
Employee & Platform Support & 0.0937 & 0.2439 & 0.1620 \\
Dedication & Platform Incentive & 0.0911 & 0.2219 & 0.1539 \\
& Platform Constraint & 0.0701 & 0.1981 & 0.1317 \\
Employee & Platform Support & 0.1437 & 0.3186 & 0.2259 \\
Absorption & Platform Incentive & 0.1403 & 0.2930 & 0.2105 \\
& Platform Constraint & 0.1218 & 0.2639 & 0.1862 \\
& Platform Support & 0.2632 & 0.4360 & 0.3446 \\
Work Engagement & Platform Incentive & 0.2166 & 0.3724 & 0.2878 \\
& Platform Constraint & 0.2113 & 0.3511 & 0.2737 \\
\hline
\end{tabular}

Table 5. Path analysis results

\begin{tabular}{|c|c|c|c|c|c|c|c|c|}
\hline \multirow[b]{2}{*}{ Action path } & \multirow{2}{*}{\multicolumn{2}{|c|}{ Mediation effect value }} & \multicolumn{2}{|c|}{ Model 1} & \multicolumn{4}{|c|}{ Model 2} \\
\hline & & & $\begin{array}{l}\text { Path } \\
\text { factor }\end{array}$ & $\mathrm{t}$ & $\mathrm{p}$ & $\begin{array}{l}\text { Path } \\
\text { factor }\end{array}$ & $\mathrm{t}$ & $\mathrm{p}$ \\
\hline & $\begin{array}{l}\text { Platform } \\
\text { Support }\end{array}$ & -0.0433 & 0.5930 & 13.5820 & 0.000 & -0.0730 & -1.2032 & 0.000 \\
\hline
\end{tabular}




\begin{tabular}{|c|c|c|c|c|c|c|c|c|}
\hline \multirow[t]{3}{*}{$\begin{array}{l}\text { Employee } \\
\text { Vigor }\end{array}$} & $\begin{array}{l}\text { Platform } \\
\text { Incentive }\end{array}$ & -0.0766 & 0.6047 & 13.1789 & 0.000 & -0.1267 & -2.1030 & 0.000 \\
\hline & $\begin{array}{l}\text { Platform } \\
\text { Constraint }\end{array}$ & -0.0443 & 0.5051 & 1.3821 & 0.000 & -0.0876 & -1.4999 & 0.000 \\
\hline & $\begin{array}{l}\text { Platform } \\
\text { Support }\end{array}$ & 0.1620 & 0.5562 & 12.1500 & 0.000 & 0.2913 & 5.3412 & 0.000 \\
\hline \multirow[t]{3}{*}{$\begin{array}{l}\text { Employee } \\
\text { Dedication }\end{array}$} & $\begin{array}{l}\text { Platform } \\
\text { Incentive }\end{array}$ & 0.1539 & 0.5079 & 10.1464 & 0.000 & 0.3029 & 5.7725 & 0.000 \\
\hline & $\begin{array}{l}\text { Platform } \\
\text { Constraint }\end{array}$ & 0.1317 & 0.4917 & 10.8248 & 0.000 & 0.2679 & 5.0531 & 0.000 \\
\hline & $\begin{array}{l}\text { Platform } \\
\text { Support }\end{array}$ & 0.2259 & 0.5969 & 13.3522 & 0.000 & 0.3785 & 6.7457 & 0.000 \\
\hline \multirow{3}{*}{$\begin{array}{l}\text { Employee } \\
\text { Absorption }\end{array}$} & $\begin{array}{l}\text { Platform } \\
\text { Incentive }\end{array}$ & 0.2105 & 0.5530 & 11.3286 & 0.000 & 0.3792 & 7.0654 & 0.000 \\
\hline & $\begin{array}{l}\text { Platform } \\
\text { Constraint }\end{array}$ & 0.1862 & 0.4883 & 10.6027 & 0.000 & 0.3813 & 7.1354 & 0.000 \\
\hline & $\begin{array}{l}\text { Platform } \\
\text { Support }\end{array}$ & 0.3446 & 0.1677 & 3.6622 & 0.000 & 0.5123 & 12.1539 & 0.000 \\
\hline \multirow{2}{*}{$\begin{array}{l}\text { Work } \\
\text { Engagement }\end{array}$} & $\begin{array}{l}\text { Platform } \\
\text { Incentive }\end{array}$ & 0.2878 & 0.2537 & 5.7425 & 0.000 & 0.5415 & 12.4554 & 0.000 \\
\hline & $\begin{array}{l}\text { Platform } \\
\text { Constraint }\end{array}$ & 0.2717 & 0.2737 & 5.8994 & 0.000 & 0.5063 & 12.7088 & 0.000 \\
\hline
\end{tabular}

From the data analysis results in Table 4, it can be seen that when employee vigor is used as a mediation variable, the confidence intervals are respectively $(-0.1123,-0.0207),(-0.1633,-0.0028)$, and $(-0.1046,-0.0122)$, not including zero. Thus, the mediation effect of employee vigor is significant; but the mediation effect value is negative $(\beta 1=-0.0433, \beta 2=-0.0766, \beta 3=-0.0443)$, indicating that platform support, platform incentives, and platform constraints are indirectly reversed through employee vigor to affect employee service performance. Therefore, it is assumed that $\mathrm{H} 2 \mathrm{a}, \mathrm{H} 2 \mathrm{~b}$, and $\mathrm{H} 2 \mathrm{c}$ have not been verified. When employee dedication is used as a mediation variable, the confidence intervals are $(0.0937,0.2439),(0.0911,0.2219)$, and $(0.0701,0.1981)$, which do not include zero. Thus, the mediation effect of employee dedication is significant; and the mediation effect value is positive $(\beta 1=$ $0.1620, \beta 2=0.1539, \beta 3=0.1317$ ), indicating that platform support, platform incentives, and platform constraints all indirectly positively affect employee service performance through employee dedication. Therefore, it is assumed that $\mathrm{H} 3 \mathrm{a}, \mathrm{H} 3 \mathrm{~b}$, and $\mathrm{H} 3 \mathrm{c}$ are verified. When employee absorption is used as a mediation variable, the confidence intervals are $(0.1437,0.3186),(0.1403,0.2930)$, and $(0.1218,0.2639)$, which do not include 0 . Thus, the mediation effect of employee absorption is significant; and the mediation effect value is positive $(\beta 1=0.2259, \beta 2=0.2105, \beta 3=0.1862)$, indicating that 
platform support, platform incentives, and platform constraints all positively affect employee service performance indirectly through absorption. Therefore, it is assumed that $\mathrm{H} 4 \mathrm{a}, \mathrm{H} 4 \mathrm{~b}$, and $\mathrm{H} 4 \mathrm{c}$ are verified.

According to the above hypothesis testing results, the conceptual model of this study was modified and improved. The final model of this study is shown in the following figure:

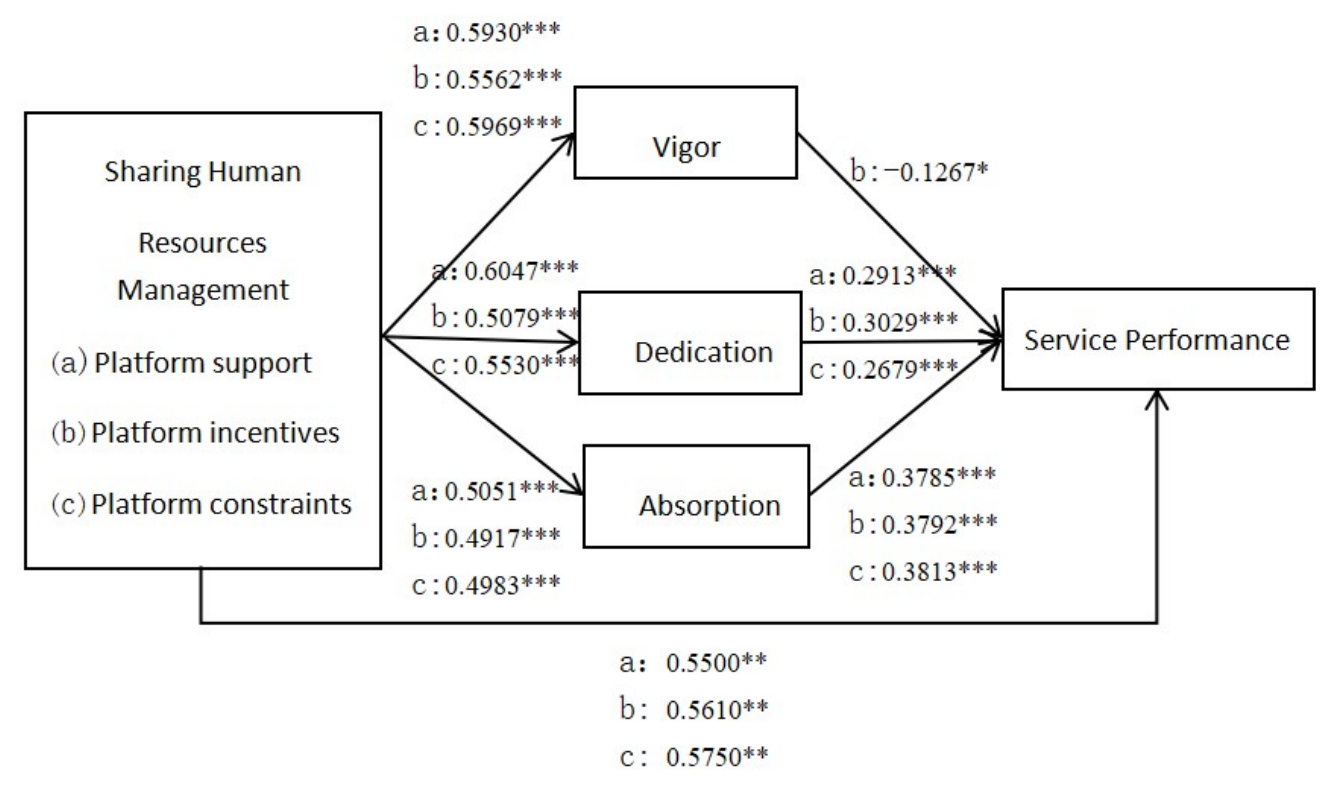

Figure 2. The Modified Theoretical Model

\section{Discussion}

\subsection{Research Conclusions and Theoretical Significance}

1. This research is based on the Organizational Support Theory, revealing how the sharing human resource management practices affect the service performance of sharing workers, and the results support the theory of organizational support. The data analysis results of the study show that platform support, platform incentives, and platform constraints all positively affect employee service performance, and such results can be well explained in the theory of organizational support; work engagement is partial mediating in sharing human resource management practices and service performance. Sharing workers with a high level of work commitment have a good mentality and mental state when working on the online ride-hailing platform, and they actively complete their order tasks; they identify themselves as online ride-hailing drivers, and go with full enthusiasm to actively meet and treat the challenges encountered in the process of driving a car. As an antecedent variable that affects employee's work engagement, the sharing human resources management practice activities affect the worker's engagement level in the job as a ride-hailing driver by affecting the employee's psychology and behavior, and the sharing worker's engagement to the job determines the final result of job performance. However, one of 
the findings in this study is really unexpected: the vigor of sharing employees plays a negative role between platform incentive and service performance. In other words, platform incentive of sharing platform can improve the vigor of employees, but the improvement of employees' vigor has a negative impact on their service performance. The possible explanation is: at present, the incentive policy in the sharing platform focuses on how to improve the work quantity of employees, that is to say, the current incentive policy is more to encourage the sharing employees to accept more tasks, the greater the incentive strength of the platform, the more the employees will receive orders. However, the ride experience of passengers is ignored in the process. In order to complete more orders, drivers may reduce services such as providing help to customers, thus reducing customer service performance. Therefore, although the incentive policy of the platform improves the vigor of employees, it reduces the service performance of customers.

2. The theoretical contribution of this research is to put forward and verify the hypothesis that sharing human resources management practices have a positive impact on employee service performance, and propose and validate the theoretical model. First, we scientifically distinguish true sharing workers in sharing platforms. Not all ride-hailing drivers are sharing workers. Only the workers who really use their idle time and idle resources are truly sharing workers, while drivers similar to taking ride-hailing drivers as their sole occupation are not. Second, we expand the research on human resource management practices of sharing workers. In previous research, the research on it mainly focused on organizational performance. This study extends the impact scope of sharing employee human resource management practices on the organization to employee service performance, and enriches the post-dependent variables of human resource management practices. Meanwhile, the research perspective is converted from the perspective of traditional human resources to the perspective of sharing human resources management. Third, in addition to studying the direct impact of sharing human resource management practices on employee service performance, we also explore the transmission mechanism between the two variables. Research results show that sharing human resource management practices can improve employee service performance by increasing employee work engagement levels. Its theoretical contribution lies in finding a key to the "black box" between sharing human resource management practices and employee service performance, and analyzing the in-depth conduction mechanism between them.

\subsection{Practical Inspiration}

1. Implementing human resource management practices based on sharing platforms

First, the sharing platform cannot adapt to traditional human resource management practices because of its uniqueness, so it should be based on the characteristics of the platform organization; second, the platform organization should value sharing workers, and clarify the importance and urgency of this emerging talent management. Finally, we need to implement corresponding management measures based on corporate practices and employee characteristics. 
Then, the specific measures to be implemented include the following ones: first, to build up work confidence and improve the feedback mechanism. The platform should help ride-hailing drivers build up their confidence and set up an independent specific department to improve the feedback mechanism, which can better help drivers solve the problems they encounter in the process of work. In organizational management, feedback is an important link between employees and the organization. According to the survey, there is a great problem in the feedback mechanism between ride-hailing platforms and ride-hailing drivers. Most drivers said that if they dispute with passengers on the way to pick up or drop off them, they will give the information back to the platform, but the platform rarely deals with the feedback of drivers. Thus, the obvious problem in the platform enterprise is that the situations of employees cannot be fed back to their superiors, and there is only a one-way flow of information between the organization and employees. Obviously, problems exist in the management of the organization. Therefore, in a sharing platform enterprise, the organization should value the construction of feedback channels, ensure the two-way flow of information between employees and the organization, and ensure the information's authenticity and timeliness and so on. Second, to raise unit salary and perfect incentive mechanism. Due to the particularity of sharing workers, how to retain excellent employees and reduce the employee turnover rate is one of the vital problems in human resource management of sharing platform enterprises. In terms of incentives, the biggest feature of ride-hailing platforms that distinguish from traditional industries lies in their reward mechanism which is the driving force of ride-hailing drivers, and the general appeal of ride-hailing drivers in the research process is to increase the unit reward. Therefore, for sharing workers, the platform organization can pay more attention to the extra bonuses and individual needs of online car-hailing drivers.

Third, to improve the qualification certification and improve the recruitment mechanism. The current human resource management systems of sharing platform enterprises show the comprehensiveness of the aspects involved, but the specific systems are not enough and the understanding and evaluation of employees are not high. When formulating human resource management practices, we should pay more attention to the specific system formulation and implementation, which is more perfect, realistic, and fair. During the interview, we found that the threshold for drivers to enter the platform was very low, and there were even cases of drivers using other people's accounts to drive. Safety accidents on Didi-platform have always been the focus of people's attention. Therefore, it is primary to improve the qualification certification of online car-hailing drivers and improve the recruitment mechanism of Didi-platform.

2. Improving employees' work engagement level

First, the organization should attach importance to the reasons for employee's departures and analyze the factors affecting the employee's ownership and satisfaction with the platform. The large staff mobility is a feature of human resources in enterprises on the sharing platform, and factors, affecting employees' sense of belonging and satisfaction on the platform to be more complex. Secondly, employees 
should be taught according to their aptitudes, and different employees should be satisfied with their different needs to improve their recognition to the organization. In the early interviews and later surveys, some downwind drivers said that if the salary of the enterprise could not satisfy them, they would give up the platform or directly give up being an online car-hailing driver. Some drivers also said that the distribution of orders is not flexible enough. Only when employees have a high sense of recognition and belonging to the organization can they create profits for the enterprise in the position of the organization. Finally, the platform should focus on cultivating the professional spirit of ride-hailing drivers. Platform enterprises should standardize the service process of drivers and improve their professional quality. And ride-hailing drivers should improve their self-cognition, cultivate correct values, enrich legal knowledge and enhance the awareness of safeguarding rights.

\subsection{Limitations and Prospects}

Taking downwind drivers among ride-hailing drivers as the research object, this study constructs and verifies the theoretical model of the impact mechanism of sharing human resource management practices on employee service performance. However, due to the limitations of time, resources and ability, there are still some deficiencies in the research: (1) For the limited time and energy, we only selected downwind drivers as the research object, so there may be some limitations in the generalization of the research conclusion. Future research can be conducted by studying and validating other types of sharing platform enterprises. (2) As this study makes a more scientific distinction to sharing workers, the difficulty of investigation is greatly increased. According to the definition of sharing workers in this study, only part-time downwind drivers are the research subjects. Therefore, the number of samples is limited, which may lead to the lack of generalization in the quality and quantity of data. (3) The research on the sharing human resource management practices is still in the exploration stage at home and abroad, and there are many other related research contents and research directions.

Based on the current research situation at home and abroad, as well as the shortcomings of this research, we make the following prospects for the future research direction: first, certain situational conditions can be added on the basis of the existing research. For example, as a "social person", will the personality traits have a certain regulating effect on the employee service performance? If so, what is the regulating effect path like? In conclusion, there are many unknowns waiting for us to explore. Second, the relevant empirical research can be further improved. This study's biggest weakness is the lack of sample size, at the same time, the survey area is small. It is desirable to be able to ensure enough sample sizes and, at the same time, to ensure the area coverage of sample data, so that the results collected can make statistics more representative and universal, finally concluding real, effective and reliable statistic effects. In fact, there are not many empirical studies on the sharing economy, and the number of theoretical studies is more than practical studies. In order to truly enjoy the fruits of the sharing economy, we must combine the sharing economy with more empirical researches. Thirdly, the incentive and restriction management of employees 
in the sharing platform enterprise can be employed. The staff of sharing platform enterprises have great mobility, so its incentive mechanism and restriction mechanism are particularly important. We can further discuss the incentive mechanism and restriction mechanism of sharing platform enterprises to increase the depth of the research.

\section{reference}

${ }^{[1]}$ Belk, R. (2014). You are what you can access: Sharing and collaborative consumption online. Journal of Business Research, 67(8): 1595-1600.

${ }^{[2]}$ Chase. (2015). Performing the sharing economy. Geoforum, (67).

${ }^{[3]}$ Belk, R. (2017). Sharing without Caring. Cambridge Journal of Regions, Economy and Society, (10): 249-261.

${ }^{[4]}$ Weber, T. A. (2016). Product Pricing in a Peer-to-Peer Economy. Journal of Management Information Systems, 33(2): 573-596.

${ }^{[5]}$ Narasimhan, C., Papatla, P., Jiang, B., Kopalle, P. K., Messinger, P. R., Moorthy, S. et al.

(2018). Sharing Economy: Review of Current Research and Future Directions. Customer Needs \& Solutions, 5(9): 1-14.

${ }^{[6]}$ Jiang, B., and Tian, L. (2018). Collaborative Consumption: Strategic and Economic Implications of Product Sharing. Management Science, 64(3): 1171-1188.

${ }^{[7]}$ Heinrichs H. (2013). Sharing Economy: A Potential New Pathway to Sustainability. GAIA Ecological Perspectives for Science and Society, 22(4):228-231(4).

${ }^{[8]}$ Tang, C., Bai, J., So, K., Chen, X., and Wang, H. (2018). Coordinating Supply and Demand on an On-demand Platform: Price, Wage, and Payout Ratio. Manufacturing \& Service and Operations Management, https://doi.org/10.1287/msom.

${ }^{[9]}$ Tian, L., and Jiang, B. (2018). Effects of Consumer-to-Consumer Product Sharing on

Distribution Channel. Production and Operations Management, 27(2): 234-250.

${ }^{[10]}$ Zervas, G., Proserpio, D., and Byers, J. (2017). The Rise of the Sharing Economy: Estimating the Impact of Airbnb on the Hotel Industry. Journal of Marketing Research,54(5): 687-705.

${ }^{[11]}$ Guda, H., and Subramanian, U. (2017). Your Uber Is Arriving: Managing On-demand Workers through Surge Pricing, Forecast Communication and Worker Incentives. Management Science, http://dx.doi.org/10.2139/ssrn.2895227.

${ }^{[12]}$ Guttentag, D., Smith, S., Potwarka, L., and Havitz, M. (2018). Why Tourists Choose Airbnb: A Motivation-based Segmentation Study. Journal of Travel Research, 53(3): 342-359.

${ }^{[13]}$ Greenwood, B. N., and Wattal, S. (2017). Show Me the Way to Go Home: An Empirical Investigation of Ride Sharing and Alcohol Related Motor Vehicle Homicide. MIS Quarterly, 41(1):163-187.

${ }^{[14]}$ Gu Yinhua, Wang Di, and Li Ping. (2017). The Exploring of Sharing Human Resource Management Mode: Based on the Grounded Theory of the Platform of Internet Chauffeured car. Chinese Human Resource Development, (8):108-116.

[15] Gu Yinhua. (2017). Practice of sharing human resource management: system construction, scale development and mechanism research. Postdoctoral report of School of management, Fudan University.

${ }^{[16]}$ Doug H. (2015). What the "sharing economy" takes. Nation, 300(7): 12-15.

${ }^{[17]}$ Hartl. (2017). Regulating the European Sharing Economy: State of Play and Challenges. Intereconomics, 52(1).

${ }^{[18]}$ Cramer J, and Krueger A B. (2016). Disruptive Change in the Taxi Business: The Case of Uber. Social Science Electronic Publishing.

${ }^{[19]}$ Donna, Maria, Blancero, et al. (2001). A process model of discretionary service behavior: Integrating psychological contracts, organizational justice, and customer feedback to manage service agents. Journal of Quality Management.

${ }^{[20]}$ Gagné M, and Deci E L. (2005). Self-determination Theory and Work Motivation. Journal of Organizational Behavior, 26(4): 331-362. 
${ }^{[21]}$ Raymond Loi, Xiaowan Lin, and Alice J.M. Tan. (2019). Powered to craft? The roles of flexibility and perceived organizational support. Journal of Business Research,104.

${ }^{[22] R h o a d e s ~ L, ~ a n d ~ E i s e n b e r g e r ~ R . ~(2002) . ~ P e r c e i v e d ~ o r g a n i z a t i o n a l ~ s u p p o r t: ~ A ~ r e v i e w ~ o f ~ t h e ~}$ literature. Journal of Applied Psychology, 87(4):698-714.

${ }^{[23]}$ Farh J L, Earley P C, and Lin S C. (1997). Impetus for Action: A Cultural Analysis of Justice and Organizational Citizenship Behavior in Chinese Society. Administrative Science Quarterly, 42(3): 421-444.

${ }^{[24]}$ Karremans, J. C. (2005). Forgiveness and Its Associations with Prosocial Thinking, Feeling, and Doing Beyond the Relationship with the Offender. Personality and Social Psychology Bulletin, 31(10):1315-1326.

${ }^{[25]}$ Fincham F, and Beach S R H. (2007). Forgiveness and marital quality: Precursor or consequence in well-established relationships? [J]. The Journal of Positive Psychology, 2(4):260-268.

${ }^{[26]}$ Jia L, Shaw, Tsui A, et al. (2014). A Social-Structural Perspective on Employee-Organization Relationships and Team Creativity. Academy of Management Journal, 57( 3) : 869-891.

${ }^{[27]}$ Malik M A R, Butt A N, and Choi J N. (2015). Rewards and employee creative performance: Moderating effects of creative self-efficacy, reward importance, and locus of control. Journal of Organizational Behavior, 36(1):59-74.

${ }^{[28]}$ Bushardt S. C., Glascoff D. W., and Doty D. H. (2011). Organizational Culture, Formal Reward Structure, and Effective Strategy Implementation: A Conceptual Model. Journal of Organizational Culture Communications \& Conflict, 15(2): 57-70.

${ }^{[29]}$ Panagiotakopoulos A. (2013). The Impact of Employee Learning on Staff Motivation in Greek Small Firms: The Employees' Perspective. Development and Learning in Organizations, 27(2): 13-15.

${ }^{[30]}$ Takeuchi R, Chen G, and Lepak D P. (2010). Through the Looking Glass of a Social System: Cross-Level Effects of High-Performance Work Systems on Employees' Attitudes. Social Science Electronic Publishing, 62(1):1-29.

${ }^{[31]}$ Ohly S, and Fritz C. (2010). Work characteristics, challenge appraisal, creativity, and proactive behavior: a multi-level studies. Journal of Organizational Behavior, 31 (4) :543-565.

${ }^{[32]}$ LePine J A, Podsakoff N P, and LePine M A. (2005). A meta-analytic test of the challenge stress-hindrance stress framework: an explanation for inconsistent relationships between stressors and performance. Academy of Management Journal, 48(1): 764-775.

${ }^{[33]}$ Shraga, O., and Shirom, A. (2009). The construct validity of vigor and its antecedents: a qualitative study. Human Relations, 62(2), 271-291.

${ }^{[34]}$ Rothbard N P. (2001). Enriching or depleting? The dynamics of engagement in work and family roles. Administrative Science Quarterly, 46(4):655-684.

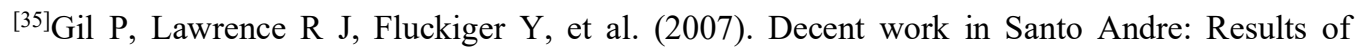
multi-method case study. Habitat International, 32(2):172-179.

${ }^{[36]}$ Rich B L, Lepine J A, and Crawford E R. (2010). Job engagement: Antecedents and effects on job performance. Academy of Management Journal, 53(3):617-635.

${ }^{[37]}$ Eisenberger R, Armeli S, Rexwinkel B, et al. (2001). Reciprocation of perceived organizational support. Journal of Applied Psychology, 86(1):42-51.

${ }^{[38]}$ Eisenberger R, Stinglhamber F, Vandenberghe C, et al. (2002). Perceived supervisor support: Contributions to perceived organizational support and employee retention. Journal of Applied Psychology 87(3):565-573.

${ }^{[39]}$ Witt L A. (2006). Exchange Ideology as a Moderator of Job Attitudes organizational Citizenship Behaviors Relationships1. Journal of Applied Social Psychology, 21(18):1490-1501.

${ }^{[40]}$ Saks A M. (2006). Antecedents and consequences of employee engagement. Journal of Managerial Psychology, 21(7):600-619.

${ }^{[41]}$ Shirom, and Arie. (2011). Vigor as a positive affect at work: conceptualizing vigor, its relations with related constructs, and its antecedents and consequences. Review of General Psychology, 15(1), 50-64.

${ }^{[42]}$ Boehm, J. K., and Lyubomirsky, S. (2008). Does happiness promote career success? Journal of Career Assessment, 16(1), 101-116. 
${ }^{[43]}$ Tsai, W. C., Chen, C. C., and Liu, H. L. . (2007). Test of a model linking employee positive moods and task performance. Journal of Applied Psychology, 92(6), 1570-1583.

${ }^{[44]}$ Schaufeli, and W. B. (2004). The measurement of work engagement with a short questionnaire: a cross-national study. Educational \& Psychological Measurement, 66(4), 701-716.

${ }^{[45]}$ Bledow R, Schmitt A, Frees M, et al. (2011). The affective shift model of work engagement. Journal of Applied Psychology, 96(6):1246-1257.

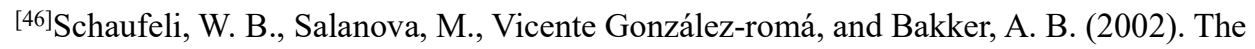
measurement of engagement and burnout: a two-sample confirmatory factor analytic approach. Journal of Happiness Studies, 3(1), 71-92.

${ }^{[47]}$ Rich B L L J. (2010). Job engagement: Antecedents and effects on job performance. Academy of Management Journal, 53(3):617-635.

${ }^{[48]}$ Kataria A, Garg P, and Rastogi R. (2013). Does psychological climate augment OCBs? The mediating role of work engagement. The Psychologist-Manager Journal, 16(4):217.

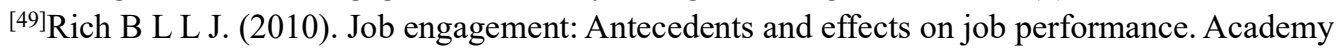
of Management Journal, 53(3):617-635.

${ }^{[50]}$ Schaufeli W B, and Bakker A B, Salanova M. (2006). The measurement of work engagement with a short questionnaire: A cross-national study. Educational and Psychological, (66):701-716.

${ }^{[51]}$ Schaufeli W B, and Bakker A B. (2004). Job demands, job resources, and their relationship with burnout and engagement: A multi-sample study. Journal of Organizational Behavior, 25(3):293-315.

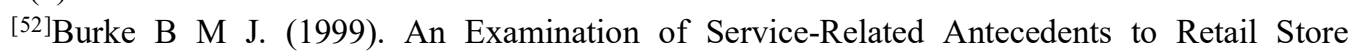
Performance. Journal of Organizational Behavior, 20(6):943-962.

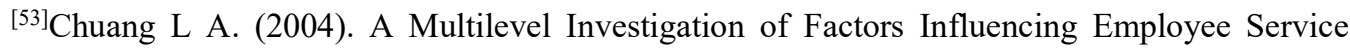
Performance and Customer Outcomes. The Academy of Management Journal,47(1):41-58.

${ }^{[54]}$ Preacher K J, and Hayes a F. (2004). SPSS and SAS procedures for estimating indirect effects in simple mediation models. Behavior Research Methods, Instruments, \& Computers, 36(4):717-731. 